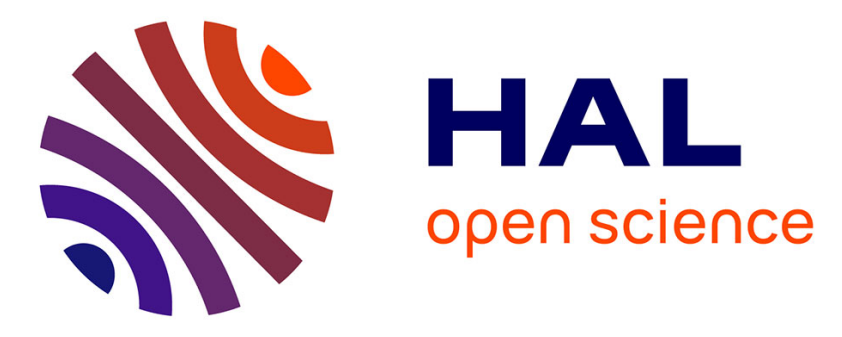

\title{
Artifact Correction for DVC Measurements Using a Laboratory X-Ray Source
}

Jérôme Adrien, Jean-Yves Buffiere, François Hild, Nathalie Limodin, Julien

Réthoré, Stéphane Roux

\section{- To cite this version:}

Jérôme Adrien, Jean-Yves Buffiere, François Hild, Nathalie Limodin, Julien Réthoré, et al.. Artifact Correction for DVC Measurements Using a Laboratory X-Ray Source. 2012 Annual Conference on Experimental and Applied Mechanics, 2012, Costa Mesa, United States. pp.217-220, 10.1007/978-14614-4235-6_30. hal-01668877

\section{HAL Id: hal-01668877 https://hal.science/hal-01668877}

Submitted on 26 Jul 2021

HAL is a multi-disciplinary open access archive for the deposit and dissemination of scientific research documents, whether they are published or not. The documents may come from teaching and research institutions in France or abroad, or from public or private research centers.
L'archive ouverte pluridisciplinaire HAL, est destinée au dépôt et à la diffusion de documents scientifiques de niveau recherche, publiés ou non, émanant des établissements d'enseignement et de recherche français ou étrangers, des laboratoires publics ou privés. 


\title{
Artifact Correction for DVC Measurements Using a Laboratory X-Ray Source
}

\author{
J. Adrien, J. -Y. Buffière, F. Hild, N. Limodin, J. Réthoré, and S. Roux
}

\begin{abstract}
The effects of temperature elevation of the X-ray tube of a lab tomograph during image acquisition are analyzed in terms of their induced biases for Digital Volume Correlation (DVC) from a series of reconstructed volumes acquired successively. Spurious dilatational strains are induced by temperature variations in the tomograph. If not accounted for, any quantitative kinematic measurement is impossible for strain levels below $0.5 \%$. When corrected, it is possible to determine the elastic parameters of nodular graphite cast iron.
\end{abstract}

\subsection{Introduction}

To visualize inside opaque materials, X-ray computed microtomography (XCMT) is becoming more and more popular. 3D reconstructed views of various materials [1,2] are obtained in a non-destructive way. Reconstructed volumes give access to the inner structure of metallic, ceramic, cementitious, and cellular materials. Damage mechanisms and cracks are also analyzed through direct visualization.

It is also possible to load samples in situ. An additional analysis consists in using the reconstructed volumes themselves to evaluate displacements. The latter are for instance measured by resorting to marker tracking [3] or Digital Volume Correlation [4]. In the following analyses, a global approach to DVC [5] will be used. The main artifact encountered in the present study is reported hereafter. The interested reader will find additional analyses and details in Reference [6].

\subsection{Material and Methods}

The material studied herein is a ferritic nodular graphite cast iron $(\mathrm{Fe}-3.4 \mathrm{C}-2.6 \mathrm{Si}-0.05 \mathrm{Mg}-0.19 \mathrm{Mn}$ wt $\%)$ containing a uniform distribution of nearly spherical graphite nodules (average diameter: $50 \mu \mathrm{m}$ ). The graphite nodules are easily imaged by tomography and used as natural markers for volume correlation of the 3D reconstructed images.

The analyses are performed using a CT system V-Tomex (Phoenix X-ray) with a nanofocus tube (W target) whose acceleration voltage is adjusted from 40 to $160 \mathrm{kV}$, and whose focal spot size can be tuned from 6 to $1 \mu \mathrm{m}$. Cast iron being strongly attenuating, the tomography experiments are carried out with a rather large spot size, i.e., $3.5 \mu \mathrm{m}$, and a 95-kV acceleration voltage to ensure a $10 \%$ transmission of the X-ray beam through the $1.5 \times 1.5 \mathrm{~mm}^{2}$ cross-section of the sample. The specimen is put on the rotating stage in the tomograph chamber between the X-ray source and an amorphous Si diode

J. Adrien • J. -Y. Buffiere $・$ N. Limodin

MATEIS, Université de Lyon, INSA-Lyon/CNRS, Villeurbanne, France

F. Hild $(\bowtie) \cdot$ S. Roux

LMT-Cachan, ENS Cachan/CNRS/Université Paris 6/PRES UniverSud Paris, 61 avenue du Président Wilson F-94235 Cachan Cedex, France e-mail: hild@1mt.ens-cachan.fr

J. Réthoré

LaMCoS, Université de Lyon INSA-Lyon/CNRS, Villeurbanne, France 


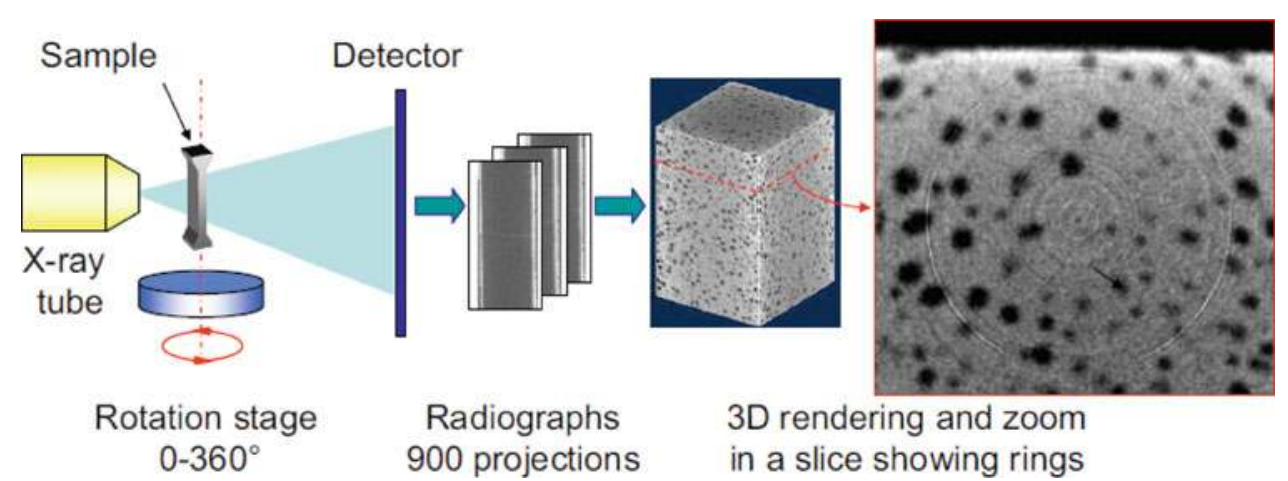

Fig. 30.1 Schematic view of the process of tomographic acquisition and reconstruction. Ring artifacts are visible on one axial cut of the reconstructed volume

array detector of definition $1,920 \times 1,536$ pixels. A set of 900 radiographs is recorded while the sample is rotating, step by step, over $360^{\circ}$ along its vertical axis. When the radiograph is shot, the rotating stage does not move. With an acquisition time per image of $500 \mathrm{~ms}$, one complete scan lasts about $45 \mathrm{~min}$. Reconstruction of the tomographic data is performed with a filtered back-projection algorithm (i.e., an optimized Feldkamp cone-beam procedure [7]) using datos x-acquisition and reconstruction software developed by Phoenix. It provides a 3D reconstructed image with a 16-bit gray scale (Fig. 30.1).

\subsection{Artifact Analysis}

When several scans are acquired successively, X-rays are emitted for about an entire day so that the temperature of the tube may vary by several tens of Celsius degrees from the first to the last scan. Variations of magnification between each radiograph, and more importantly between two scans are therefore expected. This may impact quantitatively the procedures of tomographic image acquisition with a lab tomograph that is not running $24 \mathrm{~h} / \mathrm{day}$. The following analysis is proposed to quantify this effect. Three series of scans of the same sample are acquired successively. The sample is not moved nor loaded. The displacement fields with respect to the very first scan of each series are measured by using DVC and further processed. Due to the variation of the magnification induced by the temperature variation of the X-ray tube, an homothetic transformation is looked for. The measured displacement field is thus projected in a least-squares sense onto a basis that contains the rigid body motions (i.e., three translations, and three rotations) and a (spurious) scalar dilatational strain $\varepsilon$ inducing a dilatational displacement field $\mathrm{u}=\varepsilon \mathrm{x}$.

Figure 30.2 shows the change of the estimated dilatational strain with time for the considered series. An exponential law accounts very well for the observed dilatational strain. The latter depends on the thermal expansion of the X-ray tube and its mounting stage. The temperature of the tube may be described using a first order heat equation with a loss term, leading to a first order response with an exponentially decaying distance to a steady-state value. The characteristic time is equal to $130 \mathrm{~min}$. This result shows that a warm-up time of about $3 \mathrm{~h}$ is required to avoid spurious strain levels greater than $10^{-3}$.

This observation may also shed some doubt on the quality of the reconstructed image since successive radiographs are acquired with a shifting magnification. However, systematic corrections of the sinograms between the first and last radiographs and a linearly interpolated correction as done at the reconstruction stage allows for a good reconstruction well-suited for further DVC. This correction however cannot apprehend the induced image bias between successive reconstructions.

\subsection{Influence on Strain Measurements}

An in situ tensile test is finally performed on a smooth sample. The strains that are applied to the specimen are sought. The previous procedure is applied again. If an infinitesimal strain tensor is directly searched for (in addition to translations and rotations) by considering the raw displacements, the following mean strain components are obtained 
Fig. 30.2 Change of the dilatational strain $\varepsilon$ with time for three series of experiments

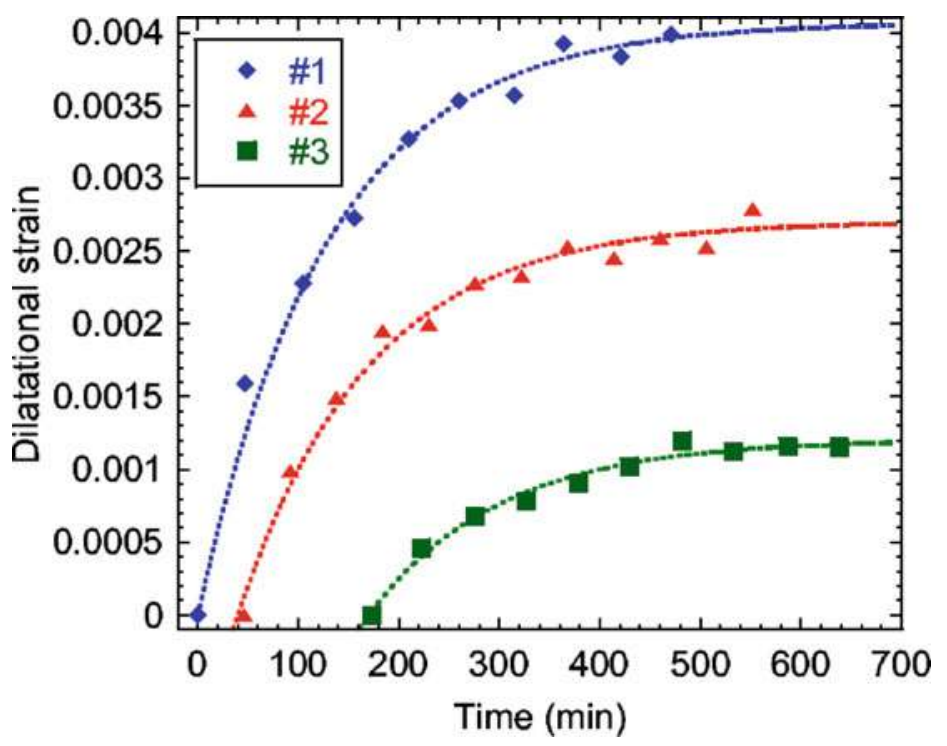

$$
\begin{aligned}
& \varepsilon_{\mathrm{xx}}=3.4 \times 10^{-3}, \quad \varepsilon_{\mathrm{xy}}=0.0 \times 10^{-3}, \quad \varepsilon_{\mathrm{xz}}=0.2 \times 10^{-3}, \quad \varepsilon_{\mathrm{yy}}=3.3 \times 10^{-3}, \\
& \varepsilon_{\mathrm{yz}}=0.4 \times 10^{-3}, \quad \varepsilon_{\mathrm{zz}}=4.8 \times 10^{-3}
\end{aligned}
$$

where $\mathrm{z}$ is the loading axis. This result is completely erroneous. Due to the linear dependence between the mechanical basis and the dilation basis, the correction and interpolation are performed in two steps. First, a projection is computed onto a basis that includes three translations, three rotations, the artificial dilatational strain and a displacement field describing a uniaxial tensile test so that the corresponding strain tensor reads

$$
\varepsilon_{\mathrm{xx}}=-v, \quad \varepsilon_{\mathrm{xy}}=0, \quad \varepsilon_{\mathrm{xz}}=0, \quad \varepsilon_{\mathrm{yy}}=-v, \quad \varepsilon_{\mathrm{yz}}=0, \quad \varepsilon_{\mathrm{zz}}=1
$$

where $v$ is Poisson's ratio of the material. For the maximum applied load level, the dilatational strain $\varepsilon=3.7 \times 10^{-3}$, and the longitudinal strain $\varepsilon_{\mathrm{zz}}=1.1 \times 10^{-3}$. This latter expectation of the longitudinal strain is at least three times less than the dilatational strain, thereby invalidating the first strain estimates. From this first projection, the dilatational strain is known, and the displacement corrected for this artifact is then projected onto a basis that contains three translations, three rotations and a field corresponding to a uniform strain state. The infinitesimal strain tensor then becomes

$$
\begin{aligned}
& \varepsilon_{\mathrm{xx}}=-0.2 \times 10^{-3}, \quad \varepsilon_{\mathrm{xy}}=0.0 \times 10^{-3}, \quad \varepsilon_{\mathrm{xz}}=0.0 \times 10^{-3}, \quad \varepsilon_{\mathrm{yy}}=-0.4 \times 10^{-3}, \\
& \varepsilon_{\mathrm{yz}}=0.2 \times 10^{-3}, \quad \varepsilon_{\mathrm{zz}}=1.1 \times 10^{-3}
\end{aligned}
$$

The estimated strain tensor is now consistent with the tensile load applied to the sample, the strain derived from the global measurement (i.e., stroke of the crosshead) being $1.0 \times 10^{-3}$ for the maximum load level. Figure 30.3 shows the change of strains as a function of the applied load. Without correction, the longitudinal strain $\varepsilon_{z z}$ is strongly overestimated due to dilatational effects. Further, the dilatational strain does not depend on the applied load but on time and its effect as compared to the reference state (first image) is thus increasing during the test. This trend is consistent with the previous observations (Fig. 30.2). After correction of this artifact, a very good agreement is reached between the corrected strain and that derived from the global measurements (based upon the crosshead stroke). With the eigen strains of the corrected strain tensor $\varepsilon_{1}<\varepsilon_{2}<\varepsilon_{3}$, the identified value of Poisson's ratio is $v=-\left(\varepsilon_{1}+\varepsilon_{2}\right) / 2 \varepsilon_{3}=0.27$, which is consistent with the known value of 0.28 [8]. Young's modulus is found to be equal to $156 \mathrm{GPa}$ in good agreement with classical values of SG cast iron $(160 \pm 3 \mathrm{GPa}[8])$. 
Fig. 30.3 Strains as functions of the load level for DVC measurements with and without corrections. The dilatational strain is also plotted. Its magnitude is larger than the longitudinal (mechanical) strain

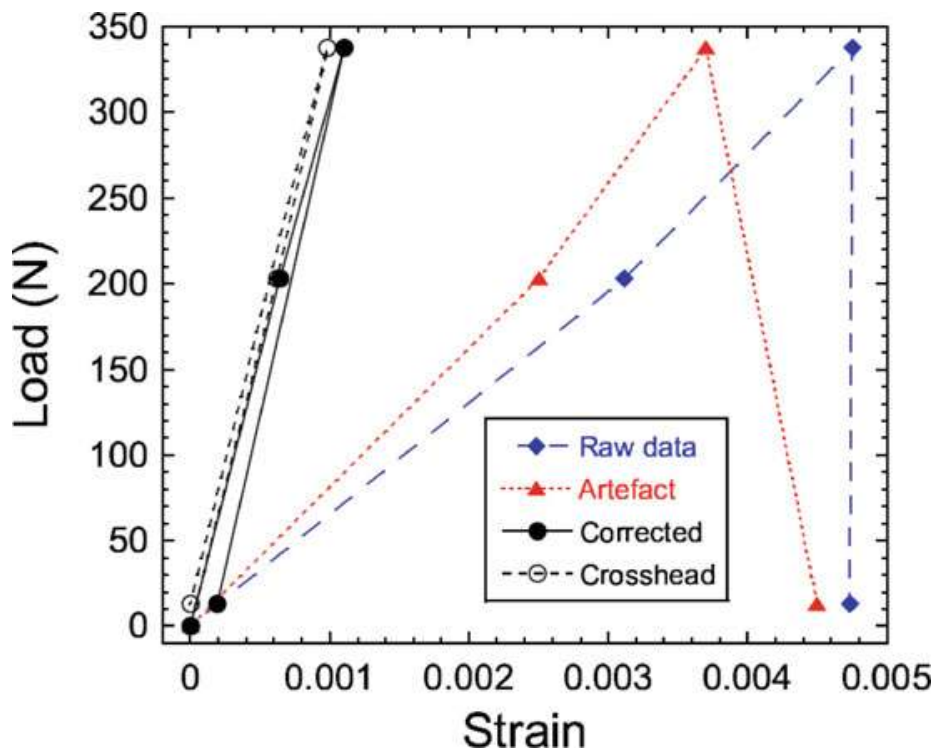

\subsection{Conclusion}

$\mathrm{X}$-ray computed tomography is a very powerful tool to visualize opaque materials. When the scans are further processed to measure displacement fields using DVC, it has been shown herein that special care should be exercised. This is particularly true for lab equipments in which divergent beams are used. In particular, if the temperature of the X-ray tube is not controlled, it may induce distance variations from the source to the sample and the detector that result in magnification changes and thus spurious dilatational strains whose maximum level (here observed to be of the order of $0.4 \%$ ) impedes any quantitative (and therefore trustful) displacement measurement. In the present case, it was shown that the elastic properties of a cast iron cannot be evaluated without a correction of the displacement field. This correction was also needed when stress intensity factors were sought in similar experiments on cracked samples [9]. In both cases, it allowed for quantitative estimates of mechanical parameters. It should however be emphasized that this artifact also impacts image reconstruction, although this effect has not been considered in the present study.

To quantify all the previous effects, the procedure followed herein is generic and can be considered as a baseline analysis to better characterize a new equipment, or an existing one when quantitative analyses such as displacement measurements are performed. In addition to spurious dilatational strains, other artifacts may include ring artifacts and beam hardening [6].

Acknowledgments This work was funded under the grant ANR-09-BLAN-0009-01 (RUPXCUBE Project).

\section{References}

1. Baruchel J, Buffière JY, Maire E, Merle P, Peix G (2000) X-ray tomography in material sciences. Hermes Science, Paris

2. Bernard D (ed) (2008) In: Proceedings of the 1st conference on 3D-imaging of materials and systems 2008, Bordeaux

3. Nielsen SF, Poulsen HF, Beckmann F, Thorning C, Wert JA (2003) Measurements of plastic displacement gradient components in three dimensions using marker particles and synchrotron X-ray absorption microtomography. Acta Mater 51(8):2407-2415

4. Bay BK, Smith TS, Fyhrie DP, Saad M (1999) Digital volume correlation: three-dimensional strain mapping using X-ray tomography. Exp Mech 39:217-226

5. Roux S, Hild F, Viot P, Bernard D (2008) Three dimensional image correlation from X-ray computed tomography of solid foam. Compos Part A 39(8):1253-1265

6. Limodin N, Réthoré J, Adrien J, Buffière JY, Hild F, Roux S (2011) Analysis and artifact correction for volume correlation measurements using tomographic images from a laboratory X-ray source. Exp Mech 51(6):959-970

7. Feldkamp LA, Davis LC, Kress JW (1984) Practical cone beam algorithm. J Opt Soc Am A1:612-619

8. Dierickx P (1996) Etude de la microstructure et des mecanismes d'endommagement de fontes G.S. ductiles: influence des traitements thermiques de ferritisation. Ph.D. thesis, INSA de Lyon

9. Limodin N, Réthoré J, Buffière JY, Gravouil A, Hild F, Roux S (2009) Crack closure and stress intensity factor measurements in nodular graphite cast iron using 3D correlation of laboratory X ray microtomography images. Acta Mater 57(14):4090-4101 